\title{
Upaya Meningkatkan Pemahaman Bahaya Bullying Melalui Bimbingan Klasikal bagi Siswa SMPN 22 Mataram
}

\author{
Ni Ketut Seriasih \\ SMPN 22 Mataram, Kota Mataram - Provinsi NTB \\ Corresponding Author. Email: niketutseriasih@ gmail.com
}

\begin{abstract}
This study aims to describe the increased understanding of the dangers of bullying through classical guidance to class VIII.A students of SMPN 22 Mataram in the 2020/2021 academic year. This research is a classroom action research. The subjects in this study were 32 students. The instrument used in this research is a questionnaire. While the data analysis technique to test the difference in the mean of the pretest and posttest after the action was carried out was using the t-test. The results showed that after being given classical guidance services, the understanding of the dangers of bullying was in the very high category with a total frequency of 23 which was $71,875 \%$. In the very high category it has reached more than half the number of students. In the high category with a total frequency of 6 of $18,75 \%$, in the medium category the number of frequency 3 of $9,375 \%$, in the low category the number of 0 is $0 \%$, the category is very low with a total frequency of 0 of $0 \%$. Thus, it can be concluded that classical guidance is an effective and innovative strategy to increase the understanding of class VIIIA students of SMPN 22 Mataram regarding the understanding of the dangers of bullying.
\end{abstract}

\begin{abstract}
Abstrak: Penelitian ini bertujuan untuk mendeskripsikan peningkatan pemahaman bahaya bullying melalui bimbingan klasikal pada siswa kelas VIII.A SMPN 22 Mataram Tahun Ajaran 2020/2021. Penelitian ini merupakan penelitian tindakan kelas. Subjek dalam penelitian ini sebanyak 32 siswa. Instrumen yang digunakan dalam penelitian ini adalah angket. Sedangkan teknik analisis data untuk menguji perbedaan rerata pretest dan posttest setelah dilakukan tindakan menggunakan t-test. Hasil penelitian menunjukkan bahwa setelah diberikan layanan bimbingan klasikal, pemahaman bahaya bullying berada pada kategori sangat tinggi yaitu dengan jumlah frekuensi 23 sebesar 71, $875 \%$. Dalam kategori sangat tinggi sudah mencapai lebih dari setengah jumlah siswa yang ada. Pada kategori tinggi dengan jumlah frekuensi 6 sebesar 18, 75 $\%$, kategori sedang jumlah frekuensi 3 sebesar 9, $375 \%$, kategori rendah jumlah 0 sebesar $0 \%$, kategori sangat rendah dengan jumlah frekuensi 0 sebesar $0 \%$. Dengan demikian, dapat disimpulkan bahwa bimbingan klasikal merupakan strategi yang efektif dan inovatif untuk meningkatkan pemahaman siswa kelas VIIIA SMPN 22 Mataram mengenai pemahaman bahaya bullying.
\end{abstract}

\author{
Article History \\ Received: 05-04-2021 \\ Revised: 06-05-2021 \\ Accepted: 22-05-2021 \\ Published: 07-07-2021
}

\section{Key Words: \\ Bullying, Classical \\ Guidance.}

\author{
Sejarah Artikel \\ Diterima: 05-04-2021 \\ Direvisi: 06-05-2021 \\ Disetujui: 22-05-2021 \\ Diterbitkan: 07-07-2021
}

\section{Kata Kunci: \\ Bullying, Bimbingan \\ Klasikal.}

How to Cite: Seriasih, N. (2021). Upaya Meningkatkan Pemahaman Bahaya Bullying Melalui Bimbingan Klasikal bagi Siswa SMPN 22 Mataram. Jurnal Paedagogy, $\quad 8(3), \quad 364-368$. doi:https://doi.org/10.33394/jp.v8i3.3763

\section{Pendahuluan}

Dasar pertimbangan atau pemikiran tentang penerapan program bimbingan dan konseling di sekolah, bukan semata-mata terletak pada ada tidaknya landasan hukum atau ketentuan dari pemerintah. Namun yang lebih penting adalah adanya kesadaran atau komitmen untuk memfasilitasi siswa agar mampu mengembangkan potensi dirinya atau mencapai tugas-tugas perkembangannya. Di sekolah yang terdiri dari berbagai karakter siswa, tak jarang terjadi suatu perbedaan pendapat, permusuhan dan lain sebagainya untuk itu 
bimbingan dan konseling mengambil peran dalam hal ini, khususnya agar pendidikan mampu berjalan secara efektif dan efisien (Romlah, 2006; Gunawan et al., 2020; Fitriatun et al., 2018; Zultoni, et al., 2020; Surodiana, 2020).

Penyimpangan perilaku kekerasan seperti tawuran, berkelahi dan lain sebagainya justru banyak dilakukan dan berawal di sekolah. Fenomena kekerasan antar siswa ini ditemukan pada hampir seluruh sekolah dari jenjang taman kanak-kanak hingga sekolah lanjut tingkat atas. Namun kesadaran sekolah untuk menanggulangi hal tersebut masih sangat rendah. Hal ini sangat ironis, karena sekolah yang seharusnya menjadi tempat yang aman dan nyaman untuk belajar harus dinodai dengan penyimpangan perilaku seperti kekerasan.

Hal lain yang lebih ironis adalah kekerasan yang harusnya semakin lama semakin berkurang justru saat ini kekerasan semakin bertambah. Sesuai dengan peraturan pemerintah dan kebijakan-kebijakan sekolah yang mengatur pendidikan, siswa memiliki hak untuk merasa aman dan memperoleh pendidikan. Tetapi nampaknya peraturan-peraturan yang ada tidak berjalan dengan baik, sehingga masih banyak kasus-kasus kekerasan atau penyimpangan lainnya yang tidak diselesaikan atau bahkan dibiarkan begitu saja. Hal ini dibuktikan dengan adanya kasus bunuh diri yang terjadi pada siswa akibat ulah temannya yang selalu menghina dan menganiayanya.

Penanganan kasus ini menyadarkan banyak pihak, sayangnya banyak pihak yang tersadar setelah adanya korban. Jika peraturan dan kebijakan yang telah ada dijalankan dengan baik dunia pendidikan tidak harus menelan korban bunuh diri. Banyaknya kasus kekerasan yang terjadi di sekolah menjadikan pendidikan tidak dapat terlaksana secara maksimal. Menurut beberapa ahli kekerasan yang terjadi di sekolah berasal dari tindakan bullying. Menurut Priyatna (2010) "satu dari tiga anak di seluruh dunia mengaku pernah mengalami bullying, baik itu di sekolah, di lingkungan masyarakat maupun di dunia maya". Begitupun sebaliknya satu dari tiga anak mengaku pernah melakukan tindakan bullying pada temannya. Bullying di sekolah bisa dilakukan oleh individu ke individu, kelompok ke individu atau kelompok ke kelompok. Tak jarang pula terjadi dari guru ke siswa. Tujuannya adalah pelaku ingin menunjukkan kekuatan kepada yang lain. Menurut Sucipto (2012) bullying dapat berbentuk fisik seperti pukulan, tendangan, tamparan, dorongan, serta serangan fisik lainnya. Yang berbentuk non fisik bullying dapat dibedakan menjadi 2 (dua), yaitu verbal maupun nonverbal. Salah satu contoh kasus bullying kasus bullying terjadi antara senior dengan adik kelasnya. Rh dipukuli seniornya ketika dia kelas VIIIA di SMP, tapi tidak ditindaklanjuti serius pihak sekolah.

Kejadian ini berawal ketika Rh kedapatan tengah berfoto-foto di lingkungan sekolah. Rupanya aksi Rh menyebabkan beberapa seniornya di SMP Negeri 22 Mataram merasa terganggu. Tiga kakak kelas Rh memaksa Rh masuk ke dalam mobil. Satu orang menyetir berputar-putar. Dua senior lainnya memukuli $\mathrm{Rh}$. Rh dipaksa telentang di bagian tengah mobil. Rusuk Rh retak parah mendekati patah. Setelah dianiaya, Rh takut masuk sekolah. Rh bahkan tidak ikut ujian mid semester dan tidak pernah mau mengatakan identitas ketiga seniornya itu. (http//.kompas.com/kekerasan.masih.terjadi.di.sekolah.htm 14 April 2020).

Keberadaan layanan bimbingan konseling di sekolah yang belum dimanfaatkan siswa secara maksimal, disebabkan karena masih banyak siswa yang belum mengetahui fungsi dan layanan bimbingan konseling. Untuk itu penting bagi guru bimbingan konseling memberikan informasi mengenai fungsi dan layanan-layanan yang ada di Bimbingan Konseling di sekolah. Selain kurang informasi mengenai keberadaan bimbingan dan konseling, guru pembimbing di sekolah biasanya juga akan memberikan layanan jika telah terjadi suatu permasalahan seperti halnya bullying. Sebelum suatu permasalah itu terjadi seharusnya ada 
upaya pencegahan terlebih dahulu, karena tindakan bullying biasanya dilakukan secara tertutup dan tidak semua siswa dan guru tahu. Untuk itu salah satu cara yang dapat digunakan yaitu memberikan informasi melalui bimbingan klasikal menggunakan teknik diskusi kelompok terhadap siswa mengenai bahaya bullying.

Berdasarkan wawancara dengan koordinator bimbingan dan konseling SMP Negeri 22 Matarampada tanggal 3 Mei 2021 dapat disimpulkan bahwa materi bahaya bullying selama ini memang belum dimasukkan dalam layanan dasar bimbingan dan konseling, selama ini memang ketika ada laporan dari siswa, atau indikasi terjadi bullying di sekolah masuk dalam layanan responif. Banyak metode yang ada dalam bimbingan klasikal, namun peneliti memilih teknik diskusi kelompok sebagai teknik yang digunakan. Alasan menggunakan teknik diskusi kelompok karena dengan menggunakan teknik diskusi kelompok dalam satu kelas, siswa dibagi menjadi beberapa kelompok untuk membahas masalah yang akan dipecahkan secara bersama.

Dalam hal ini peneliti akan memberikan masalah yang terkait dengan bullying. Menurut Muro (dalam Romlah 2006) "diskusi kelompok tidak hanya untuk memecahkan masalah tetapi juga untuk mencerahkan suatu persoalan, serta untuk pengembangan pribadi". Siswa dilatih untuk memecahkan masalah bullying yang banyak terjadi di sekolah, selain itu melatih kemampuan sosial siswa jika dipossisikan pada diskusi kelompok yang melibatkan beberapa orang di dalamnya. Teknik diskusi kelompok ini juga digunakan agar pada suatu saat ketika siswa dihadapkan pada permasalahan bullying, siswa tersebut mampu menghadapi dan menyelesaikannya sendiri. Selain itu bimbingan klasikal ini melibatkan seluruh siswa di kelas, sehingga siswa akan mendapat materi yang sama mengenai bullying. Peneliti berharap dengan mendapatkan materi yang sama akan mengurangi tindakan bullying bagi siswa yang pernah melakukan bullying, dan mencegah terjadinya bullying bagi siswa yang belum pernah melakukan tindakan bullying.

Adapun penelitian ini bertujuan untuk mendeskripsikan efektivitas penerapan metode bimbingan klasikal dengan teknik diskusi kelompok dalam meningkatkan pemahaman bahaya bullying pada siswa kelas VIIIA di SMP Negeri 22 Mataram tahun ajaran 2020/2021.

\section{Metode Penelitian}

Metode yang digunakan dalam penelitian ini adalah Penelitian Tindakan Kelas (PTK). Subyek penelitian ini adalah siswa kelas VIII.A SMP Negeri 22 Mataram tahun ajaran 2020/2021 yang berjumlah 32 siswa. Instrumen pengumpulan data yang digunakan adalah angket. Sedangkan teknik analisis data untuk menguji perbedaan rerata pretest dan posttest setalah dilakukan tindakan menggunakan $t$-test.

\section{Hasil Penelitian dan Pembahasan}

Penelitian ini dilakukan untuk mendeskripsikan pelaksanaan bimbingan klasikal dapat meningkatkan pemahaman siswa mengenai bahaya bullying pada siswa kelas VIII.A SMP Negeri 22 Mataram tahun ajaran 2020/2021. Untuk itu, peneliti melakukan pengumpulan data dengan cara prosedur ilmiah. Penelitian ini dilaksanakan 2 siklus yaitu siklus I dan siklus II.

Tabel 1. Kategori Skor Distribusi Frekuensi Data Pemahaman Bahaya Bullying Setelah diberi Tindakan (Posttest)

\begin{tabular}{|c|c|c|l|}
\hline Interval & Frekuensi & F \% & \multicolumn{1}{|c|}{ Kategori } \\
\hline $30-40$ & 23 & $71,875 \%$ & Sangat Tinggi \\
\hline $23-29$ & 6 & $18,75 \%$ & Tinggi \\
\hline $17-22$ & 3 & $9,375 \%$ & Sedang \\
\hline
\end{tabular}




\begin{tabular}{|c|c|c|l|}
\hline $10-16$ & - & - & Rendah \\
\hline $0-9$ & - & - & Sangat Rendah \\
\hline Total & 32 & $100 \%$ & \\
\hline
\end{tabular}

Bagi anak-anak yang sudah terlibat bullying maka sebagai proses rehabilitasi perlu dilakukan penyaluran minat dan bakat dengan tepat ke dalam berbagai kegiatan-kegiatan ekskul di sekolah, maupun di luar sekolah. Penyesuaian diri siswa dengan lingkungan sosial serta pengembangan diri dalam mengembangkan potensi positifnya juga perlu dilakukan dalam langkah pengentasan.

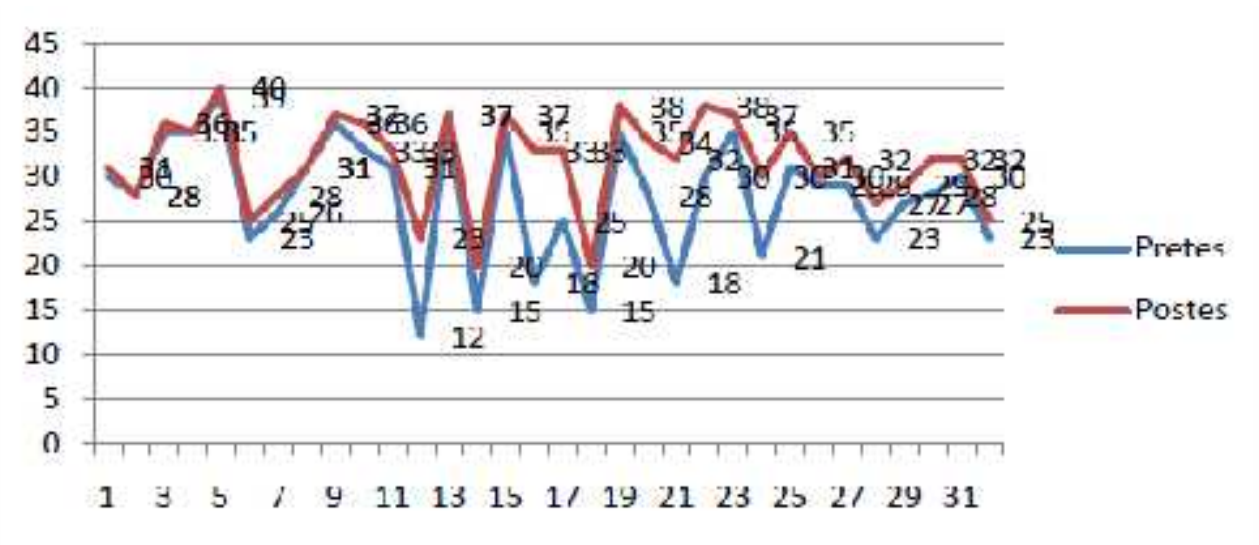

Gambar. 1 Peningkatan Skor Pemahaman Bahaya Bullying Siswa Kelas VIII A Sebelum dan Setelah diberi Layanan Bimbingan Klasikal

Tingkat pemahaman siswa tentang bahaya bullying sebelum (pretest) dan sesudah (posttest) diberikan layanan bimbingan klasikal ada pergeseran garis yang menunjukkan adanya peningkatan skor pemahaman siswa tentang bahaya bullying sebelum (pretest) dan sesudah (posttest) diberi layanan bimbingan klasikal. Sebelum diberi layanan bimbingan klasikal (pretest) sebagaimana Gambar 1, skor siswa yang berada pada kategori sangat rendah berjumlah 0 siswa., pada kategori rendah berjumlah 3 siswa, pada kategori sedang berjumlah 6 siswa, pada kategori tinggi berjumlah 8 siswa, dan kategori sangat tinggi 15 siswa. Setelah diberi layanan bimbingan klasikal (posttest) skor pemahaman siswa mengenai bahaya bullying mengalami peningkatan yang signifikan. yaitu skor siswa yang berada pada kategori sangat rendah berjumlah 0 siswa, pada kategori rendah berjumlah 0 siswa, pada kategori sedang berjumlah 3 siswa, pada kategori tinggi berjumlah 6 siswa dan pada kategori tinggi berjumlah 23 siswa.

\section{Kesimpulan}

Berdasarkan hasil penelitian yang diperoleh dapat disimpulkan bahwa siswa antusias dan merasa senang ketika pelaksanaan bimbingan klasikal yang membahas tentang bahaya bullying berlangsung. Penggunaan bimbingan klasikal merupakan strategi yang efektif dan inovatif untuk meningkatkan pemahaman siswa kelas VIII ASMP Negeri 22 Mataram mengenai pemahaman bahaya bullying. Ada peningkatan pemahaman bahaya bullying melalui bimbingan klasikal pada siswa kelas VIII ASMP Negeri 22 Mataram. Siswa yang memiliki pemahaman bahaya bullying pada kategori rendah dan sedang hendaknya lebih aktif dalam mencari berbagai informasi agar pemahamannya terus meningkat, seperti membaca koran, majalah dan melalui internet. Bagi siswa yang berada pada kategori tinggi dan sangat tinggi hendaknya dipertahankan dan diharapkan mampu berbagi informasi dengan teman- 
temannya yang belum tahu atau kurang tahu mengenai bahaya bullying. Informasi mengenai bahaya bullying tersebut dapat dicari melalui berbagai media yang sekarang sudah semakin maju.

\section{Saran}

Adapun saran yang dapat disampaikan berdasarkan hasil penelitian ini adalah hasil penelitian ini dapat dijadikan sebagai bahan rujukan bagi guru bimbingan dan konseling dalam upaya meningkatkan pemahaman bahaya bullying pada siswa, dapat melalui layanan bimbingan klasikal di sekolah.

\section{Daftar Pustaka}

Fitriatun, E., Nopita, N., \& Muliyani, S. (2018). Karakter Empati Dalam Konseling Teman Sebaya Pada Masa Remaja. Jurnal Kependidikan: Jurnal Hasil Penelitian dan Kajian Kepustakaan di Bidang Pendidikan, Pengajaran dan Pembelajaran, 4(1), 16-23. doi:https://doi.org/10.33394/jk.v4i1.897

Gunawan, I., Hartati, A., \& Mulachela, F. (2020). Pengaruh Konseling Kelompok Terhadap Perilaku Agresif Siswa di SMKN 4 Mataram. Jurnal Paedagogy, 7(4), 385-392. doi:https://doi.org/10.33394/jp.v7i4.2881

Kompas.com. "Kekerasan Masih Terjadi Sekolah. "file:///G:/skripsi/Kekerasan.Masih.Terjadi.di.Sekolah.htm. yang diunduh tanggal 14 April 2020, 07.30 WIB.

Priyatna, Andi. (2010). Let's End Bullying (Memahami, Mencegah \& Mengatasi Bullying). Jakarta: Grasindo

Romlah, Tatiek. (2006). Teori dan Praktek Bimbingan Kelompok. Malang: Universitas Negeri Malang.

Sanders, E, Cheryl dan Phye, D, Gary. (2004). Bullying implication for The Clasroom. London : Elsevier Academic Press.

Suharsimi, Arikunto. (2019). Penilaian dan Penelitian Bidang Bimbingan dan Konseling. Yogyakarta : Aditya Media.

Sucipto. (2012). Bullying dan Upaya Meminimalisasikannya. PSIKOPEDAGOGIA Jurnal Bimbingan dan Konseling Universitas Ahmad Dahlan, 1(1): 19-30.

Surodiana, S. (2020). Peran Kearifan Lokal Suku Sasak di Era Disrupsi dalam Menangkal Perilaku Menyimpang pada Kalangan Siswa di MAN 1 Lombok Timur. Jurnal Paedagogy, 7(3), 156-167. doi:https://doi.org/10.33394/jp.v7i3.2646

Yusuf, Syamsu. (2006). Program Bimbingan dan Konseling di Sekolah. Bandung : Pustaka Bani Quraisy . (2009). Program Bimbingan dan Konseling di Sekolah. Bandung: Rizqi Press Walgito, Bimo, (2004). Pengantar Psikologi Umum. Yogyakarta : Andi. www.merdeka.com, diakses 20 Agustus 2019.

Zultoni, J., \& Herna Astuti, F. (2020). PENGARUH LAYANAN KONSELING INDIVIDU

$\begin{array}{lcrrr}\text { TERHADAP PENYESUAIAN } & \text { DIRI SISWA } & \text { DI } & \text { SMAN } & 2 \\ \text { PRINGGARATA. Jurnal Paedagogy, } & 3(2), & 45-51 . \\ \text { doi:https://doi.org/10.33394/jp.v3i2.3036 } & & & \end{array}$

